\title{
Kernos
}

Revue internationale et pluridisciplinaire de religion grecque antique

5 | 1992

Varia

\section{Euhemeri Messenii Reliquae edidit Marcus}

WINIARCZYK

\section{Bruno Rochette}

\section{CpenEdition \\ Journals}

\section{Édition électronique}

URL : http://journals.openedition.org/kernos/1083

DOI : 10.4000/kernos. 1083

ISSN : 2034-7871

\section{Éditeur}

Centre international d'étude de la religion grecque antique

Édition imprimée

Date de publication : 1 janvier 1992

ISSN : 0776-3824

\section{Référence électronique}

Bruno Rochette, «Euhemeri Messenii Reliquae edidit Marcus winIARCZYK », Kernos [En ligne], 5 | 1992, mis en ligne le 20 avril 2011, consulté le 24 septembre 2020. URL : http://journals.openedition.org/ kernos/1083 ; DOI : https://doi.org/10.4000/kernos.1083 
magistrature amène l'A. à une conclusion ultime : ne serait-il pas possible de dresser un vocabulaire institutionnel de la Grèce qui tînt compte d'une répartition ethnique? Pour alléchante qu'elle soit, une telle piste de recherche ne pourra être exploitée que lorsque l'on disposera, pour chaque magistrature particulière, de travaux préliminaires du type de celui de J. Winand.

Prudence, fermeté, minutie : telles sont les qualités essentielles de ce travail qui, en étudiant une fonction précise, met bien en lumière "l'extrême morcellement et l'infinie variété du peuplement grec».

Bruno ROCHETTE (Liège)

Evhemeri Messenii Reliquae edidit Marcus WINIARCZYK, StuttgartLeipzig, Teubner, 1991, 1 vol., 14 × $20 \mathrm{~cm}$, XXXVII+76 p. (Bibliotheca Scriptorum Graecorum et Romanorum Teubneriana).

Auteur d'un curieux ouvrage intitulé L'inscription sacrée, Evhémère de Messine, qui voyait dans certains dieux des hommes divinisés pour leurs bienfaits, marque l'aboutissement d'un long effort d'explication rationnelle des mythes inaugurée par Philon d'Alexandrie et Plutarque. De cette œuvre intéressante, il ne reste, hélas, que quelques fragments que G. Némethy réunit pour la première fois voici un peu plus d'un siècle. Malgré tout le soin que le savant avait apporté à la constitution de son recueil, beaucoup de témoignages lui avaient échappé. Après F. Jacoby qui, dans sa grande édition des fragments d'historiens grecs, présente un choix de textes d'Évhémère, G. Vallauri donna, en 1956, une nouvelle édition des fragmenta et des testimonia, incomplète et surtout trop peu critique. Une remise à jour de ce travail s'avérait donc nécessaire. M. Winiarczyk s'est acquitté de cette tâche ingrate avec beaucoup de bonheur. Non content de présenter un relevé exhaustif des testimonia, le philologue polonais a doté son édition de notes critiques très étoffées présentant toutes les variantes textuelles, sans négliger le moindre détail. En outre, le travail comporte une bibliographie très complète et trois indices. Autant dire que cette excellente édition constituera désormais un outil de référence très précieux.

Bruno ROCHETTE (Liège) 